\title{
Junior baccalaureate nursing students: Factors that predict success
}

\author{
Ellen M.T. Smith* \\ Department of Nursing, Utica College, United States
}

Received: June 30, 2020

Accepted: August 6, 2020

Online Published: August 17, 2020

DOI: $10.5430 /$ jnep.v10n12p1

URL: https://doi.org/10.5430/jnep.v10n12p1

\begin{abstract}
Baccalaureate nursing education strives toward comprehensive preparation of diverse nursing students to meet current healthcare workforce demands. Identification of factors that predict academic success is imperative to meet this goal. The purpose of this study was to discover whether specific academic and noncognitive variables predicted baccalaureate nursing students' academic success, as defined by junior-year grade point average (GPA) and persistence in nursing education. This post-facto correlational study was conducted over two semesters. Junior year nursing students $(N=150)$ answered the Short Grit Survey and the Noncognitive Questionnaire, and their academic records were examined for previous college grades (GPAs) and SAT scores. Demographic groups were compared using $t$-tests, and the data were regressed on junior-year student GPAs and persistence in the major to determine predictors of success. Several significant differences between the participant group responses were noted. Only early-college GPAs predicted junior-year success. SAT scores, grit and noncognitive factors, as well as demographic variables, did not predict academic success. These results inform baccalaureate education programs about priorities for admitting and advising students, and support the use of early-college GPAs to predict the academic success of junior-year baccalaureate nursing students.
\end{abstract}

Key Words: Academic success, Baccalaureate nursing students, Multiple regression, Noncognitive variables, Nursing education

\section{BACKGROUND}

Baccalaureate nurses of diverse backgrounds are needed to match the nation's growing and increasingly heterogeneous patient population. ${ }^{[1,2]}$ Improving baccalaureate nursing student success will aid in this goal because students of color (SOCs) are more likely to earn a baccalaureate nursing degree than their White peers, advancing a more diverse group of nurses. ${ }^{[3]}$ While $48.4 \%$ of White nurses complete nursing degrees beyond the associate degree level, $52.5 \%$ of African American, 51.5\% Hispanic, and 75.6\% Asian nurses earn baccalaureate degrees. ${ }^{[3]}$ Therefore, predicting baccalaureate nursing student academic success impacts not only individual students; it also enhances the diversity of the nursing workforce.

Yet nursing student attrition rates are unacceptably high, ${ }^{[4,5]}$ and are often due to poor academic performance. ${ }^{[6]}$ Even though SOCs are more likely to earn baccalaureate degrees, they are also at risk for withdrawing or being dismissed from nursing education programs. ${ }^{[6-8]}$ The college admission process for nursing major applicants relies on academic markers such as high school grade history and standardized test scores. ${ }^{[5]}$ Some nursing programs also rely on commercial entrance examinations and prior science grades in an attempt to admit applicants who are more likely to succeed. ${ }^{[9-11]}$ Attrition imposes unacceptable financial and social costs for

*Correspondence: Ellen M.T. Smith; Email: esmith@utica.edu; Address: Department of Nursing, Utica College, United States. 
students as well as higher education institutions, ${ }^{[6,7,11]}$ and slows progress toward meeting nursing workforce demands.

Recently, the American Association of Colleges of Nursing (AACN) has promoted more holistic admission practices that consider student applicants based on their "experiences, attributes and academic metrics", ${ }^{[12]}$ in conjunction with demonstrated academic performance to diversify nursing education programs. Research on noncognitive factors that lead to nursing student success has been conducted. For example, Dapremont interviewed Black nurse graduates about factors that led to their academic success, ${ }^{[13]}$ and found "grittier"[14] activities such as deliberate, scheduled reading and study time, peer study groups and/or note cards were important. ${ }^{[13]}$ Grit also correlated with perceived academic and clinical success among surveyed Australian baccalaureate nursing students $(\mathrm{n}=2349) .{ }^{[15]}$ Similarly, psychological hardiness, experience and socio-economic support were predictive of academic persistence among nursing students in an integrative literature review. ${ }^{[5]}$ Johnson et al. found that noncognitive variables including self-concept, support, leadership, discrimination, community service, and long-range goals were identified as potential factors affecting academic success among under-represented nursing students $(\mathrm{N}=375){ }^{[16]}$ Research about noncognitive variables including grit grounds the AACNs holistic admissions practices and this research.

Within the context of desired diversity, this study investigated the extent to which academic and noncognitive variables accurately predicted baccalaureate nursing students' academic success, as defined by junior-year grade point average (GPA) and persistence in nursing. This study is important to inform nursing program admissions processes, to enhance overall student success, and enrich the nursing workforce. The need for diversity among nurses and alarmingly high attrition rates make this study imperative.

\section{METHOD}

To examine variables that may predict academic success, a convenience sample $(N=150)$ of baccalaureate nursing majors at a small, liberal arts college in the northeast United States were surveyed. The participant pool was comprised of 166 nursing majors in their junior year, and were primarily White (68\%) and female (84\%). Only third (junior) year nursing majors were invited to participate because they had completed the pre-requisite sciences and liberal arts courses and were beginning their professional nursing (laboratory and clinical) classes. Over one-fifth of all nursing students fail to persist through this educational juncture, as the nursing curriculum becomes more rigorous. ${ }^{[17]}$ Prediction of outcomes at this time was desired to optimize academic success. Academic success was defined as GPA and persistence in the nursing major during the junior year.

This post-facto correlational study was conducted over two semesters for three consecutive cohorts of nursing majors (2012-2014). Each cohort of students was surveyed near the start of the third (junior) year of a four-year academic program, following an informed consent process approved by the college's Institutional Review Board. Survey responses were analyzed in conjunction with respondents' early-college GPAs and SAT scores ${ }^{[18]}$ using IBM SPSS (versions 20-23). Following descriptive statistical assessment, regression analyses determined the relative contributions of noncognitive as well as academic variables toward GPAs (multivariate regression) and persistence (logistic regression) during the junior year. Nine noncognitive variables, two academic variables, and four demographic variables were regressed in various combinations on GPA and persistence in the junior year (two measures of academic success). A power analysis was conducted for each regression equation, and the sample size was determined to be sufficient.

The survey for this study was created by combining the Short Grit Scale (Grit-S) ${ }^{[19]}$ and the Noncognitive Questionnaire (NCQ). ${ }^{[20,21]}$ The Grit-S is an eight-item Likert-type survey to measure grit, a term defined by two distinct constructs, perseverance (effort) and passion (sustained interest) for longterm goals. ${ }^{[19]}$ Respondents rated themselves on a scale of 1 (not like me at all) to 5 (very much like me) on items such as "I am a hard worker" and "New ideas and projects often distract me from previous ones". ${ }^{[19]}$ Multiple studies of this relatively short, simple instrument confirmed its two-factor structure (sustained effort and interest), consensual and predictive validity. Internal consistency ratings of the Grit-S were .73-.83 and confirmatory factor analysis indicated acceptable goodness of fit indices among four independent samples. Test-retest reliability was adequate, computed by Pearson's correlation, $r(279)=.68, p<.001 .^{[19]}$ The Grit-S had predicted college GPAs, educational attainment, military academy retention ${ }^{[19,22-24]}$ and most recently nursing student success. ${ }^{[15]}$ The Grit-S was chosen for this study because of the promising research about $i^{[15,19,22-24]}$ and related constructs (i.e. resilience, ${ }^{[25]}$ intention to complete the degree $^{[26]}$ ), and the concerning attrition rates among nursing students. ${ }^{[4,5]}$

The NCQ was designed to address perceived racial disparities in admission processes and measure student characteristics not captured by standardized tests. ${ }^{[20,21]}$ Sedlacek established construct validity through principle component factor analysis, and identified eight constructs that defined student traits such as adjustment, motivation, and perceptions. Eighteen items on the NCQ used Likert-scaled items (1-strongly 
disagree to 5-strongly agree) to query attitudes, behaviors, and perceptions. ${ }^{[20]}$ Additionally, the NCQ inquired about educational goals, and included three short answer items regarding students' past activities and experiences. ${ }^{[20,21]}$ These items were scored numerically, and a second rater chose $40 \%$ of surveys at random, then coded the open-ended items on the chosen sample of surveys. Scores were compared, and inter-rater reliability was .96. Item coding disagreement was discussed and resolved to achieve $100 \%$ agreement. The NCQ Likert scale items had appropriate test-retest reliability, $r(1,963)=.85, p<.001$. The NCQ inter-rater reliability of the short answer questions regarding goals, community service, leadership and activities ranged from .88 to $1.0 .{ }^{[20]} \mathrm{Sim}$ ilar to the Grit-S, the NCQ revealed noncognitive factors that impacted academic success among many under-represented student groups in previous studies such as Black students ${ }^{[27]}$ and NCAA Division I athletes ${ }^{[28]}$ among others. ${ }^{[21]}$ The literature search revealed no recent evidence of NCQ research, and no studies of nursing student groups. Yet, Sedlacek's research on noncognitive variables ${ }^{[21]}$ was the foundation of the AACN Holistic Admissions Review Toolkit ${ }^{[12]}$ and pointed to a need for more noncognitive research about nursing students. The survey for this study combined the Grit-S and the NCQ to explore noncognitive factors that contributed to junior-year baccalaureate nursing student success. These factors, along with academic factors and demographic variables were regressed using multiple and logistic regression to identify predictors of junior-year GPA and persistence.

\section{Results}

The survey respondents included $94 \%$ of the institution's enrolled junior nursing students over the three years of data collection. Chi-square and $t$-tests confirmed that the cohorts were similar in terms of age, gender, and race distribution (C1 $N=50 ; \mathrm{C} 2 N=47 ; \mathrm{C} 3 N=53$ ). As no significant differences were detected, the cohorts were combined to form one group for further analyses $(N=150)$. Women $(N=126,84 \%)$ comprised the majority of participants, and $84 \%$ were under the age of 25 years. The students of color (SOC) consisted of Black, Hispanic, Asian, Multiracial and Other categories, and made up 29\% of this sample. Demographic data was self-reported, and missing demographic data was collected through a review of academic records as disclosed in the informed consent.

Among the participants, significant variation was noted between genders. GPAs following the junior year ranged from 2.49 to $3.93(M=3.16, S D=.28)$. Women $(M=3.19, S D=$ .27) earned significantly higher junior-year GPAs than men $(M=3.10, S D=.29 ; t(119)=-2.21 ; p=.03$, two-tailed $t$-test), though male and female nursing students persisted at

Published by Sciedu Press similar rates through the junior year. Women also reported more community service and more knowledge acquired in an academic field (also called nontraditional knowledge) than their male counterparts.

Comparing race and age via $t$-tests, no other differences were found to contribute to academic success. Multiple regression analyses (multivariate and logistic) did not discover any combinations of demographics that led to overall academic success as measured by junior-year GPA or persistence following the junior year.

The Grit-S scale scores of the participants ranged from 2.0 to 5.0, with a mean of $3.89(S D=.49)$. Independent samples $t$-tests showed no difference in grit between male and female participants. This study demonstrated that students aged 22 years and older reported significantly more grit $(M=4.07$, $S D=.48)$ than students aged 19-21, $(M=3.81, S D=.48), t$ $(98)=-2.39, p=.02$, with a medium effect size $(d=-.52)$. The independent samples $t$-test also demonstrated that SOC scored significantly higher on the Grit-S than White students $(M \mathrm{~s}=4.14(.48)$ vs. $3.79(.49), t(98)=3.43, p=.001)$, with a large effect size $(d=.76)$. In contrast to their grit scores, SOC scored significantly lower $(M=13.28, \mathrm{SD}=1.75)$ on the noncognitive variable of available support person than White students $(M=13.88, S D=1.32) ; t(148)=-2.29, p$ $=.02$, with a medium effect size $(d=-.41)$. These results indicate that SOC were grittier and less supported in college than White students.

GPAs during the initial years of college were found to be statistically predictive of GPAs and persistence in the junior year of the four-year nursing program. The most parsimonious simultaneous regression to predict junior-year GPA included just two independent variables, gender and prior college GPA. These two variables significantly predicted junior-year GPA, $F=(2,109)=24.92, p<.001(N=112)$. The model accounted for $31 \%$ of the variance $(R$ squared $=.314$ ), and both variables were significant predictors. In other words, females and students who earned higher grades in pre-nursing college courses were likely to earn higher GPAs in their junior year of the nursing major. Though the total respondents numbered 150, only students still enrolled in nursing classes at the end of the junior year and had earned prior GPAs from the studied institution were included in this equation to maintain consistency of measurement $(N=112)$.

Similarly, the logistic regression to predict persistence through the junior year revealed that the strongest predictor was previous college GPAs, with an odds ratio of 7.2. Gender was not a significant predictor of persistence as it was for the junior-year GPA. This indicated that students with the highest early-college GPAs were seven times more 
likely to persist in the nursing major than those with lower GPAs prior to taking nursing classes. Following several iterations of multiple and logistic regression equations, SAT scores were not found to predict GPA or persistence in the junior year. Furthermore, noncognitive variables, including grit, were not found to be significant contributors to GPA or persistence in the junior year.

\section{Discussion}

This sample was similar the nation-wide demographic profile of baccalaureate nursing students, as $84 \%(N=126)$ of participants identified as females between 19 and 24 years old, and $71 \%(N=107)$ self-identified as White. ${ }^{[29]}$ Though sampling procedures precluded generalization of the results, nurse educators in comparable nursing programs interested in student success can learn from this work. The NCQ and the Grit-S surveys had not previously been used among junior-level baccalaureate nursing students, so this study is informative as nurse educators seek predictors of academic success for student nurses from diverse backgrounds.

In this study, nursing student responses differed in several ways. For instance, female participants earned statistically higher GPAs during their junior year of college than their male counterparts. Although several authors ${ }^{[30-32]}$ have explored gender-based marginalization and the experiences of men in nursing, little quantitative research has compared academic success based on gender in the nursing major, so this finding begs further inquiry.

Grit scores were not significantly different between genders in this study. However, a similar study of nursing students in South Korea found that men had more grit than women, a finding possibly attributable to cultural differences. ${ }^{[33]}$ Older student participants reported higher grit scores than students under 22 years of age. Grit likely increases with life experience, as observed in previous studies that found positive correlations between grit and age, ${ }^{[22,34]}$ so these findings were not surprising.

Grit scale scores were significantly higher among nursing SOC than their White peers in this study. Because SOC have historically lacked resources to facilitate college entrance, and have been under-represented in colleges ${ }^{[24,34]}$ it follows that the SOC in this study possibly faced more challenges and had more internal motivation toward a long-term goal such as college than White students as noted in their Grit-S scores. In previous studies, nursing SOC described determination to complete their baccalaureate degrees despite challenges and barriers, although grit was not quantitatively assessed. $^{[26,34]}$ Similar to the students in this study, Strayhorn $^{[23]}$ found that Black men in college reported relatively high grit scale scores $(M=4.08, S D=.88)$. In sum, nursing SOC's grit scores in this study were consistent with previous research among SOC, even though higher grit scores did not predict students' overall academic success when regressed on junior-year GPAs and persistence. These disparate results indicate the need for additional research, especially about historically under-represented groups such as men and SOC in baccalaureate nursing programs.

Previous reports ${ }^{[19,21,28]}$ have advocated that noncognitive variables, including grit, predicted academic success among various samples of college students, and grit recently predicted perceived performance among nursing students. ${ }^{[15]}$ Contrary to those studies, these results inform nurse educators that noncognitive variables, grit, and SAT scores do not predict academic success for junior-year nursing students. To predict academic success and persistence, nurse educators should rely on GPAs earned during the initial years of college, consistent with previous findings. ${ }^{[8,10]}$

The NCQ had not surveyed college students recently, and studies of grit among college students have demonstrated inconsistent results. Historically, the Grit-S was touted for predicting success among distinct groups of students, including military academy cadets, ${ }^{[19]}$ pharmacy students, ${ }^{[22]}$ and Black men attending predominantly White colleges. ${ }^{[23]}$ However, a follow-up study of military cadets found that grit was not the most reliable predictor of performance and retention, ${ }^{[35]}$ similar to the meta-analysis findings of Crede, Tynan and Harms. ${ }^{[36]}$ The mixed results about grit indicate a need for further research among diverse student groups.

In this study, only early college GPAs predicted nursing student academic success as measured by junior-year GPA and persistence in the nursing major. This reinforces Wambuguh, Eckfield \& Van Hofwegen ${ }^{[10]}$ and Williams et al., ${ }^{[8]}$ whose studies found previous GPAs to be predictive of academic performance. A fundamental finding of this work was that SAT scores did not predict GPAs or persistence through the junior year for nursing students, in contrast to a meta-analysis that found standardized nursing entrance exams and SATs predicted nursing success. ${ }^{[37]}$ Nurse educators are advised to reconsider the value of students' SAT performance based on this finding. Similarly, students' age and race did not impact academic success in this study. These findings differ from Tartavoulle et al. ${ }^{[11]}$ who found nursing students who were older and SOC were less likely to be academically successful. Again, previous college GPAs were consistent predictors of success, whereas noncognitive variables, SAT scores, and demographic variables did not predict academic success for junior year nursing students.

There are several limitations of this study. The surveys relied 
on self-reported data, which is inherently subjective and risks inaccuracy, though the use of established survey instruments in this research minimized this concern. ${ }^{[38]}$ Potential confounding variables, such as family history or financial status may also have influenced student success, but were beyond the scope of this study. Additionally, systemic factors such as institutional climate, faculty biases and student support resources likely impact student success, but were not addressed in this study. These contextual factors are important considerations when assessing nursing student success.

\section{Conclusion}

This study examined how academic and noncognitive variables in combination predicted baccalaureate nursing students' academic success during their junior year. The results of this study indicate that early-college GPAs predict junioryear success as measured by GPAs and persistence better than SAT scores or the noncognitive variables evaluated in this study, consistent with the results of previous studies of nursing students. ${ }^{[6,8,10]}$ The results of this study affirm the value of early-college GPAs as predictors of junior-year success. This work also informs nurse education programs that aim to admit student applicants of various backgrounds to diversify the nursing workforce. A gap in current literature about students' success in the junior year of baccalaureate nursing programs drives this synthesis and points to areas for further research about academic success among nursing students.

The use of data-driven decisions is vital to maximizing both program resources and optimal student outcomes. The participants studied were demographically similar to other baccalaureate nursing students at small, liberal arts and professional four-year colleges, and nurse educators interested in baccalaureate student success will benefit from applying this evidence to inform strategies for admissions and advising. The results of this study are important because an understanding of predictive factors such as previous college GPAs will result in improved student outcomes and a more diverse nursing workforce.

\section{ACKNOWLEDGEMENTS}

The author expresses their appreciation to the nursing students who participated in this study, and the faculty that enabled their success.

\section{CONFLicts OF INTEREST Disclosure}

The author declares that there is no conflict of interest.

\section{REFERENCES}

[1] American Association of Colleges of Nursing, AACN. Diversity, equity and inclusion in academic nursing: AACN position statement. American Association of Colleges of Nursing. 2017. Available from: http://www.aacn.nche.edu/education-resources/

[2] Phillips JM, Malone B. Increasing racial/ethnic diversity in nursing to reduce health disparities and achieve health equity. Public Health Reports. 2014; 129(suppl2): 45-50. PMid:24385664 https ://doi.org/10.1177/00333549141291S209

[3] American Association of Colleges of Nursing, AACN. Fact sheet: enhancing diversity in the workforce. American Association of Colleges of Nursing. 2014. Available from: http://www. aacn.nche.edu/ media-relations/fact-sheets/enhancing-diversity

[4] Harris RC, Rosenberg L, O'Rourke G. Addressing the challenges of nursing student attrition. J Nurs Educ. 2014; 53(1): 31-37.

[5] Olsen JM. Integrative review of admission factors related to associate degree nursing program success. J Nurs Educ. 2017; 56(2): 85-93. PMid:28141882 https://doi.org/10.3928/01484834-20170 123-05

[6] Mitchell KM, Chorney MA, Gural DM, et al. Social and academic integration strategies for retention of nursing students: a scoping review protocol. JBI Database System Rev Implement Rep. 2019; 17(1): 28-36. PMid:30629040 https : //doi .org/10.11124/JBI SRIR-2017-003745

[7] Denham SA, Tietzew M, Allam Z, et al. Academic success of undergraduate nursing students. Nurse Educ Pract. 2018; 33: 172-177. PMid:30237070 https : //doi.org/10.1016/j.nepr.2018. 08 .013

Published by Sciedu Press
[8] Williams LB, Bourgault AB, Valenti M, et al. Predictors of underrepresented nursing students' school satisfaction, success, and future education intent. J Nurs Educ. 2018; 57(3): 142-149. PMid:29505071 https : //doi.org/10.3928/01484834-20180221-03

[9] Knauss P, Willson P. Predicting early academic success: HESI admissions assessment exam. J Prof Nurs. 2013; 29(25): 528-531.

[10] Wambuguh O, Eckfield M, Van Hofwegen L. Examining the importance of admissions criteria in predicting nursing program success. Int J Nurs Educ Scholarsh. 2016; 13(1): 87-96. PMid:27744415 https://doi.org/10.1515/ijnes-2015-0088

[11] Tartavoulle T, Adorno M, Garbee D, et al. Predictors of success in BSN students. Int J Nurs Educ Scholarsh. 2018; 15(1). PMid:29543588 https://doi.org/10.1515/ijnes-2017-002 8

[12] American Association of Colleges of Nursing, AACN. Holistic admissions review toolkit. Leading Initiatives. American Association of Colleges of Nursing. 2016. Available from: http://www . aacn .nche.edu/education-resources/holistic-review

[13] Dapremont JA. Black Nursing Students: Strategies for Academic Success. Nursing Education Perspectives. 2014. PMid:24988718 https://doi.org/10.5480/11-563.1

[14] Duckworth AL. Grit. The Power of Passion and Perseverance. New York, NY: Scribner; 2016.

[15] Terry D, Peck B. Academic and clinical performance: What's grit got to do with it? Nurse Education Today. 2020; 88: 1-6. PMid:32092601 https://doi.org/10.1016/j.nedt.2020.104371

[16] Johnson CW, Johnson R, Kim M, et al. Personal background preparation survey of nursing students at risk for attrition. Journal of 
Nursing Education. 2009; 48(11): 606-613. PMid:19650609 https : //doi.org/10.3928/01484834-20090716-06

[17] Pitt V, Powis D, Levett-Jones T, et al. Factors influencing nursing students' academic and clinical performance and attrition: an integrative literature review. Nurse Educ Today. 2012; 32: 903-13. PMid:22595612 https : //doi.org/10.1016/j.nedt.2012.04 .011

[18] CollegeBoard. About the SAT suite of assessments. 2016. Available from: https://collegereadiness.collegeboard.org/abou $\mathrm{t}$

[19] Duckworth AL, Quinn PD. Development and validation of the short grit scale (Grit-S). J Pers Assess.2009; 91(2): 166-174. PMid:19205937 https://doi.org/10.1080/00223890802634 290

[20] Sedlacek W. Beyond the Big Test: Noncognitive Assessment in Higher Education. San Francisco, CA: Jossey-Bass; 2004.

[21] Sedlacek W. Measuring Noncognitive Variables: Improving Admissions, Success, and Retention for Underrepresented Students. Sterling, VA: Stylus Publishing; 2017.

[22] Pate AN, Payakachat N, Harrell TK, et al. Measurement of grit and correlation to student pharmacist academic performance: a multicenter study. Am J Pharm Educ. 2017; 81(6): 105. PMid:28970606 https://doi.org/10.5688/ajpe816105

[23] Strayhorn T. What role does grit play in the academic success of black male collegians at predominantly white institutions? J Afr Am Stud. 2014; 18(1): 1-10. https://doi.org/10.1007/s12111-0 12-9243-0

[24] Wolters CA, Hussain M. Investigating grit and its relations with college students' self-regulated learning and academic achievement Metacogn Learn. 2015; 10: 293-311. https ://doi .org/10.100 7/s11409-014-9128-9

[25] Beauvais AM, Stewart JG, DeNisco S, et al. Factors related to academic success among nursing students: a descriptive correlational research study. Nurse Educ Today. 2014; 34(6): 918-923. PMid:24380623 https://doi.org/10.1016/j.nedt.2013.12 .005

[26] Evans DB. Examining the influence of noncognitive variables on the intention of minority baccalaureate nursing students to complete their program of study. J Prof Nurs. 2013; 29(3): 148-154. PMid:23706967 https://doi.org/10.1016/j.profnurs. 2012.04.016
[27] Nasim A, Roberts A, Harrell JP, et al. Noncognitive predictors of academic achievement for African Americans across cultural contexts. J Negro Educ. 2005; 74(4): 344-378.

[28] Ting SR. Impact of noncognitive factors on first year academic performance and persistence of NCAA Division I student athletes. J Humanist Educ Dev. 2009; 48(2): 215-228. https ://doi.org/10 .1002/j.2161-1939.2009.tb00079.x

[29] American Association of Colleges of Nursing, AACN. Ten years of race/ ethnicity data. American Association of Colleges of Nursing. 2015. Available from: http://www.aacn.nche.edu/research -data/EthnicityTbl.pdf

[30] Carnevale T, Priode K. "The good ole' girls' nursing club": the male student perspective. J Transcult Nurs. 2018; 29(3): 285-291. PMid:28826326 https ://doi.org/10.1177/10436596177031 63

[31] DeVito J. The experience of male nursing students. Nurs Forum. 2016; 51(4): 246-253. PMid:26549349 https://doi.org/10.1 $111 /$ nuf . 12149

[32] O’Lynn CE, Tranbarger R. Men in Nursing: History, Challenges, and Opportunities. New York: Springer Publishing Company, LLC; 2007.

[33] Se-Won K. Nursing students' grit: a cross-sectional study. Advances in Social Sciences Research Journal. 2018; 5(10): 127-131. https://doi.org/10.14738/assrj.510.5303

[34] Young-Brice A, Dreifuerst KT. Exploring grit among black prelicensure nursing students. Nurs Educ Perspect. 2019; Feb 22(0): 1-3.

[35] Maddi S R, Matthews MD, Kelly DR, et al. The continuing role of hardiness and grit on performance and retention in West Point cadets. Mil Psychol. 2017; 29(5): 355-358. https ://doi.org/10.1037/ mil0000145

[36] Credé M, Tynan MC, Harms PD. Much Ado About Grit: A MetaAnalytic Synthesis of the Grit Literature. Journal of Personality and Social Psychology. 2017; 113: 492-511. PMid:27845531 https : //doi.org/10.1037/pspp0000102

[37] Grossbach A, Kuncel NR. The predictive validity of nursing admission measures for performance on the national council licensure examination: A meta-analysis. Journal of Professional Nursing. 2011; 27: 124-128. PMid:21420045 https://doi.org/10.1016/j.pr ofnurs.2010.09.010

[38] Fowler FJ. Survey research methods. 4th ed. Los Angeles: Sage; 2009. 